\title{
Makrokosmos III
}

\author{
Enn Kasak, Roomet Jakapi
}

\begin{abstract}
Teesid
Uusaegsele teaduslikule ja religioossele mõtlemisele oli omane ühesugune aja kulgemise skeem kirjeldamaks lineaarset makrokosmilist ajaskaalat. Kõigepealt toimus maailma ja inimese loomine ja inimese pattulangemine ning umbes kaks aastatuhandet hiljem järgnes sellele suur veeuputus. Ajaskaala keskel seisis Kristuse ristisurm ja ülestõusmine ning peagi saabub ka maailma lõpp. Inimesi ootab kas siis igavene õndsus taevas või piinad põrgus. Arutlusteemaks võis olla küsimus, mis toimub hingega pärast surma ja enne kohtumõistmist.

Uusaegne religioossus mõjutab olulisel määral ka tänaseid arusaamu teadusest.
\end{abstract}

Märksõnad: teaduse ajalugu, teadusfilosoofia, lõpmatus, religioon, uusaja filosoofia, ülestõusmine.

Enn Kasak: Täna oli meil plaanis natukene vaadelda ajaskaalasid, makrokosmilist ja mikrokosmilist ajaskaalat.

Roomet Jakapi: Sellesama ajastu kontekstis, millest me räägime, tuleks muidugi alustada algusest, n-ö alfast ja jõuda välja oomegani. Seda võib võtta lineaarse skeemina maailma algusest lõpuni välja. On selge, et see maailm algab siis, kui ta luuakse. Just nimelt luuakse. Tollal peeti peaaegu mõeldamatuks seda, et universumil on algus ja enne seda pole midagi. Midagi peab olema alati olemas olnud. Küsimus on ainult selles, kas see, mis alati olemas on olnud, on vaimne või materiaalne olev. Valdav seisukoht, nagu me oleme juba märkinud, oli selline, et niisuguse suurepärase universumi sai valmis teha ainult mingi väga tark ja seega vaimne olev/olend [ingl $\mathrm{k}$ Being], kes on alati eksisteerinud.

Enn Kasak: Oleks väga naljakas ette kujutada, et meil on näiteks hunnik savi, hunnik liiva, tükk mingisugust rauda vedelemas ning kui see nüüd lihtsalt segiläbi raputada, siis peaks tekkima see ilus maailm, peaksid tekkima need ilusad loomad, need ilusad taimed.

Roomet Jakapi: Veelgi kummalisem on ette kujutada, et savist ja liivast (või üldisemalt: pelgast mateeriakuhjatisest) tekib inimmõistus. Inimene tuleb ikka valmis teha, nii keha kui hing. Maailma 
loomist, loomade, taimede ja inimese loomist kirjeldatakse 1. Moosese raamatu kahes esimeses peatükis. Sellele, kes usub, et piibel on sõna tõsises mõttes Jumala Sõna ja ilmutus, - ja tüüpiline varasema uusaja mõtleja seda uskus - on siin nii või teisiti tegemist tõsilugudega. Küsitavaks jääb vaid see, kuidas täpselt neid jumalikke tõsilugusid tõlgendada. Nagu me eespool seletasime, tollal oli igati mõistlik arvata, et maailm on loodud vaid mõni tuhat aastat tagasi. See arvamus näis olevat kooskõlas nii pühakirja kui mõistusega. Vabamõtlejate kahtlused ja vastuargumendid ilmselt enamust ei veennud. Sest öelda, et maailm on palju vanem, võib-olla igavene, tähendanuks öelda, et piibel valetab ja seega ei olegi Jumala Sõna. Säärane patune järeldus oli enamuse jaoks täiesti vastuvõetamatu. Loomisest järgmine oluline sündmus meie skeemil on ilmselt inimese pattulangemine. Täpsemalt: Aadama ja Eeva - esimeste inimeste - elu paradiisis, nende pattulangemine ja paradiisist välja ajamine (1. Moosese rmt, ptk 3-4). Järgmine meie arutelu seisukohalt oluline sündmus on suur veeuputus. Nagu nägime, püüdis William Whiston seda sündmust täpselt dateerida. Veeuputuse toimumisaeg oli muidugi vaieldav. Üldiselt arvati, et see toimus tuhatkond aastat või ka veidi rohkem pärast loomist.

Enn Kasak: Erinevate variantide järgi toimus see tuhandest kuni kahe tuhande aastani pärast maailma loomist. Keskeltläbi arvati, et läks umbes poolteist tuhat aastat, enne kui maailmale vesi peale tõmmati. Seda kõike arvestati hoolikalt, teaduseraamatud ühes ja piibel teises käes.

Roomet Jakapi: Oluline on siinkohal rõhutada seda, et uusaegse teaduse rajajate jaoks ei olnud kõnealused piiblilood mitte luiskelood ega muinasjutud lastele ja lihtsameelsetele, vaid neid võeti tõesti tõena, kirjeldusena sellest, kuidas asjad juhtusid. Muidugi otsiti mõistlikku balanssi päris sõnasõnalise ja üdini allegoorilise piiblikäsitluse vahel, aga laias laastus kehtis arusaam, et selles pühas raamatus on kirjas jumalik, ilmutatud tõde. Neil seal ja tollal polnud mõtlemise taustaks seesugust teaduslikku maailmapilti, mis on tänapäeval valdav.

Enn Kasak: Ega see tänapäeval valdav teaduslik maailmapilt ka nüüd pattudest päris prii ole ning võib-olla jõuame neistki kunagi rääkida. Ka tänapäevase teadusliku maailmapildi aluseks on ikkagi usaldav uskumus ning ausalt öeldes oleme sama pimedad nagu 
vanastigi. Peaasi on, et enamus eksiks korraga. Siis on meil tunne, et kui me kõik koos eksime, siis meil on ju õigus.

Roomet Jakapi: Hämmastav, kuidas ühel või teisel perioodil valdavad inimesi ühed või teised kollektiivsed uskumused, millest nii entusiastlikult kinni haaratakse.

Enn Kasak: Bryan Magee on öelnud hästi, et kui üldse midagi filosoofia ja teaduse ajaloos kindlat on, siis on see, et iga järgneva põlvkonna arvates olid eelmised põlvkonnad jaburad ja uskusid erakordseid lollusi. Meil ei ole mingit alust pidada ennast selles jadas erandiks.

Seejuures võib osutuda, et mõndagi sellest, mida tänapäeval mõni isik räägib, kiidetakse 200-500 aasta pärast väga suureks tõeks. Aga meie õnnetuseks ei suuda me seda suurt tõde jamade hulgast üles leida.

Tulles selles võtmes veeuputuse juurde tagasi, arvestagem, et tegemist oli väga tõsise teadusega, kus rehkendati ja arutleti veeuputuse kestuse üle, veehulga üle veeuputuses, selle veehulga päritolu üle jpm. Appi võeti ning leiutati mitmesugused kosmilised teooriad, alates komeetidest kuni selleni välja, et vesi lihtsalt liigutati või tõmmati mingisse asendisse. Nii et seda tehti väga tõsiteaduslikult.

Roomet Jakapi: Jah, võiks öelda, et veeuputus oli tõsine teaduslikteoloogiline või teoloogilis-teaduslik probleem. Kui nüüd seda ajaliini pidi edasi liikuda, siis kusagil on Kristuse sündimisaeg, mille järgi aega rehkendatakse. Sellele järgneb Kristuse ristilöömine ja ülestõusmine. Kristuse kui inimkonna Lunastaja sünd, õpetusejagamine, surm ja ülestõusmine on meie maailma ajaskeemis teatud mõttes kesksed ja kõige olulisemad sündmused alfa ja oomega vahepeal.

Enn Kasak: Võib-olla sama oluline võis olla ka siiski loomise hetk ja ütleme, et ka pattulangemise hetk. Kuid tõsi on see, et Kristuse ülestõusmine on keskne sündmus kindlasti meie jaoks, see on koht, kust alates on tegelikult võimalik juba ajaloost rääkida. Kristus on ju sündinud siiski ajaloolisel ajal, ehkki seda väidet on paljud vaidlustanud. Igatahes on jutt sel puhul ajaloolisest ajast, kuid loomise ja veeuputuse toimumise aja üle võis tõepoolest vaielda. Nii et ülestõusmisele kui keskpunktile tuginedes võis oma kosmoloogiat üpris mõnusalt edasi arendada. 
Roomet Jakapi: Pärast Kristuse ülestõusmist asuti muidugi ootama tema tagasitulekut ja oodatakse tänapäevani. Siit jõuame maailma lõpu problemaatika juurde. Uusajal leidus endiselt mitmesuguseid arvamusi selle kohta, millal see maailm võiks otsa saada, aga nii või teisiti pidi see aeg varem või hiljem kätte jõudma. Ja kindlasti arvati seda saabuvat märksa lähemas tulevikus, kui me tänapäeval üldse oleksime võimelised uskuma.

Enn Kasak: Juba ristiusu esimestel sajanditel usuti viimsepäeva küllaltki kiiret saabumist ja see usk pole siiani kuhugi kadunud. Oma elu jooksul olen kuulnud palju viimsepäeva kuupäevi, neid oli igas eelmise sajandi kümnes, oli aastal 2000 ja järjest neid juurde ennustatakse.

Roomet Jakapi: Jah, eks nende ettekuulutustega ole alati see häda, et välja kuulutatud kuupäevad jõuavad kätte, kuid midagi ei juhtu.

Enn Kasak: Aga teisest küljest, kui viimnepäev väga kaugesse tulevikku lükata, siis see idee ei müü jälle ennast sugugi.

Roomet Jakapi: Praegune "internatsionaalse terrorismi" ajajärk pakub ilmselt taas kord suurepäraseid võimalusi ilmalõpu kuulutamiseks.

Enn Kasak: Maailm on nüüdseks nii globaalne, et minu teada praegu üks kõige populaarsemaid maailmalõpu teooriaid on seotud hoopis maajade usundiga. Nende arvates saabub maailma lõpp 23. detsembril 2012. See on ka juba piisavalt lähedal, nii et võibolla ei suudagi uued maailmalõpu teooriad niipea sellega arvestatavalt konkureerida, kuigi see pole välistatud.

Roomet Jakapi: Naastes meie skeemi juurde: on mõeldamatu, et maailmal polnud algust, aga samuti, et sel ei tule lõppu.

Enn Kasak: Ja maailma lõpp peab ju lähedal olema, see on ju selge. Vaadakem ainult natuke ringi ja rakendagem oma mõistust. Me ju näeme, mis jama igal pool toimub, ja täpselt sama tunne on olnud kõikide aegade inimestel. Pole raske taibata, miks on usutav, et maailma lõpp ei ole enam kaugel.

Roomet Jakapi: Ja mis siis maailma lõpus juhtub? Tuleb surnute ülestõusmine. Johannese ilmutusraamatu järgi (ptk 20) on neid üles- 
tõusmisi kaks, nende vahele mahub aga tuhandeaastane rahuriik maapeal, mil Saatan on aheldatud, aga Kristus elab ja valitseb ühes märtritega, kes on osa saanud esimesest ülestõusmisest. Teiste sõnadega, esmalt "tõusevad ellu" kristlikud märtrid, ülejäänud surnud jäävad veel tuhandeks aastaks "ellu tõusmata".

Enn Kasak: Ja muuseas ei tasu arvata, et ülestõusmise idee on jäänud mingisse 17.-18. sajandisse, vaid see elab praegugi jõuküllast elu. Nii näiteks võib praegugi igaüks tellida Tulane’i Ülikooli (New Orleans) matemaatilise füüsika professori Frank J. Tipleri suurepärase raamatu pealkirjaga "Surematuse füüsika". Ja seal on väga põhjalikult analüüsitud, kuidas kõik, mis on lubatud pühakirja järgi, võib tegelikult realiseeruda. Selle üle on raamatus väga tõsiselt ja teaduslik-filosoofiliselt arutletud. Selgub, et ülestõusmine, igavene elu jmt on tulevikus täiesti reaalsed, kui inimkond jõuab oma arengus nn "oomega" punkti, kus ta omandab n-ö jumaliku kvaliteedi. Kuna aeg pole siis enam takistuseks, siis on pühakirja lubadused teostatavad ka meie suhtes, kes me täna siin elame. Sellelaadseid ideid on kirjanduslikult tutvustanud meile Dan Simmons oma "Hüperioni" sarjas. Enamik füüsikuid on taolised teooriad muidugi tagasi lükanud ja kaunis muigava suuga, aga raamat on igati lugemist väärt. Tipleri seisukohti tuntakse ka kurikuulsa antroopsusprintsiibi variandina, mida nimetatakse totaalseks antroopsusprintsiibiks. Selle järgi siis inimvaim areneb ja areneb ja areneb kuni "oomega" punkti jõudnuna tekib n-ö lõpmatuslik mõistus ehk Jumal, kelle jaoks aeg ja ruum ei ole enam piiravateks faktoriteks. Jumalat küll praegu veel pole, kuid ta tekib tulevikus. Ja kuna Jumala jaoks on kogu aeg kui tervik kättesaadav, siis on ta pärast tekkimist ka minevikus (seega ka praegu) tegelikult olemas. Tema on ka see, kes meie maailma lõi sellisena, et inimene saaks siin elada, tema antud lubadused on jõus ning õiglasi inimesi ootab igavene elu. Tipler on väga põhjalikult näidanud, kuidas kõik pühakirja lubadused realiseeruvad. Selline tõlgendus sobib väga hästi ka juba 21. sajandisse.

Roomet Jakapi: Nüüd aga tollest teisest ülestõusmisest. Kui tuhat aastat rahuriiki otsa saab, siis tõusevad surnuist üles kõik ülejäänud inimesed, sealhulgas ka need patused, kes....

Enn Kasak: ...osutuvad Jumalast äratõugatuks.

Roomet Jakapi: Just. See ülestõusmise lugu on andnud ainest paljudele õudusfilmidele ja muule sedalaadi loomingule. Rahuriigi 
lõppedes päästetakse Saatan mõneks ajaks lahti ja seejärel heidetakse ta tule- ja väävlijärve. Viimaks toimub kohtumõistmine inimeste üle. Lõppjaam või õieti kaks lõppjaama, kuhu inimeste hinged ja kehad peaksid välja jõudma, on taevas ja põrgu. Taeva puhul on selge, et need, kes pärast kohtumõistmist sinna pääsevad, jäävad sinna igaveseks ja neil on seal kahtlemata väga hea olla. Selle nimel tasub siin maa peal pingutada, panna vastu igasugu kiusatustele ja ahvatlustele, võib-olla isegi loobuda maistest naudingutest. Eks ole kummalisel kombel hedonistlik lähenemine, kõik see enesepiitsutamine ja -näljutamine, ülimas vaguruses elamine - kõik selleks, et pälvida taevased naudingud.

Enn Kasak: Võib aru saada, miks Immanuel Kant oli sedalaadi vaga elu suhtes irooniline, ta ei jäägi nii väga kaugele sellest perioodist. Kant ütles, et juhul, kui ma ainult sellepärast elan õiglast elu, et saada tulevikus selle eest preemiat, siis ei maksa see elu mitte midagi. Maksab ainult see, mida ma teen kohusetundest. Peaksime rõõmustama, et taevaväravas on Peetrus, aga mitte Immanuel Kant, sest vastasel juhul oleks kõik see munkade ja nunnade pingutus lausa asjata.

Taeva asukoha kohta tahaks öelda, et selle paigutamine ei olnud väga raske probleem; taevas on enamasti paigutatud ikka kinnistähtede sfääri taha. Ja kui lauldakse, et "seal tähtede taga, kus lehvivad palmid ...", siis need on need palmid, mis lehvivad sealsamas kinnistähtede taga.

Roomet Jakapi: Taeva asukoha kohta öeldut tuleks võtta pigem sõna-sõnalt kui metafoorina. Siin ei peeta silmas mingit abstraktset teispoolsust.

Enn Kasak: Meie universum on nagu suletud tervik, meil on vaja teisi dimensioone välja mõelda, aga tolleaja inimese kosmoloogiline maailmapilt ei nõudnud erilist teispoolsust. Milleks veel mingit muud teispoolsust leiutada, mingit dimensiooni välja mõelda, kui on olemas koht, kuhu taevas panna, väga loomulik koht. On koht teispool kinnistähtede sfääri.

Roomet Jakapi: Nüüd peaks rääkima ka nendest, kellel pärast surma ja ülestõusmist sugugi nii hästi ei lähe, st nendest, kes kohtumõistmisel süüdi mõistetakse. Tollal vaieldi tuliselt küsimuse üle, mis neist õnnetuist patuseist õieti saab. Selge oli see, et nad peavad 
saama kätte oma karistused maapeal sooritatud pahategude eest, aga vaieldavaks jäi põrgupiinade kestus. Traditsioonilise arusaama kohaselt pidid põrgupiinad kestma igavesti. Kuid ajajärgul, mida meie käsitleme, hakkas see hirmuäratav põrgukujutelm mõnevõrra lahjenema. Hakati arutlema, et äkki see ei ole ikka õiglane, kui ajalike kuritööde eest igavesti karistatakse. Õiglus on ju üks Jumala olulisi atribuute. Õiglane Jumal ei saa lasta patuseid igavesti piinata. Pigem laseb mõnda aega piinata ja seejärel lõplikult hukata. Või on hukkamõistetuilgi viimaks lootus oma hinge surmast päästa? Arutleti, kas pühakiri, Jumala Sõna, ikka annab tunnistust igavestest põrgupiinadest või ei.

Enn Kasak: Muidugi seondub põrguga veel palju probleeme. Richard Sorabji eeskujul võime ühte neist tutvustada: Ükskord ühes kongis palvetab üks munk, tal on paha olla, tal on probleem. Kongi laskub ingel talle nõu andma. Ja munk räägib asja ära. "Ma ei saa aru, miks võib minna nii, et ma teen üheainsa patuteo elus, kuid mind mõistetakse igaveseks ajaks põrgupiinadesse. Selle üheainsa patuse teo eest võin ma osutuda hukkamõistetuks igaveseks ajaks. Ja samal ajal keegi, kes on terve elu elanud patus, võib osutuda üheainsa teo eest õigeksmõistetuks, nagu näiteks röövel ristipuus, kellele ju öeldi, et "veel samal päeval pead sa minuga paradiisis olema". Ma olen väga mures, miks ei võiks Jumal asju nii korraldada, et näiteks need, kes on natuke pattu teinud, need võiks olla põrgus vaid ühe päeva aastas. Näiteks jõululaupäeval saadetakse spetsiaalselt põrgusse need, kes on pattu teinud, ja ülejäänud 364 päeva saavad nad paradiisis olla. Kes on rohkem pattu teinud, need võiks näiteks 3 päeva aastas põrgus olla. Neil patustel, kes on teinud ühe heateo, lastakse paar päeva paradiisis olla. Niiviisi oleks ju asi palju õiglasem."

Ingel vastab mungale: "Aga sa oled ju haritud mees ja matemaatikat õppinud, mõtle natukene. Kui karistus oleks lõpliku aja peale, siis olnuks su jutt mõttekas, aga kuna karistus on igavene, siis tuleb välja, et mõlemad isikud, nii peaaegu pühak kui ka peaaegu antipühak oleksid nii põrgus kui ka paradiisis ühepalju, lõpmata palju päevi. Ja see ei oleks enam õiglane. Kuna karistus on igavene, siis ei jää Jumalal midagi muud üle, kui inimene kas õigeks või hukka mõista." Nii et selle igavese karistusega kerkivad üles väga huvitavad probleemid. Muu hulgas on ingli vastuski tegelikult üpris pealiskaudne. Siin on tegemist lõpmatute hulkade omadusega, mille 
järgi lõpmatu hulga lõpmatu osahulk võib olla sama võimas kui hulk ise. Kuid see ei tähenda, et sel osahulgal oleks sama kvaliteet, mis algsel hulgal. Ehk teiste sõnadega: mõelge ise, et kas pole erinev, kui ma pean igavesti istuma 364 päeva katlas ja ühe päeva palmi all ning seda järjest kogu aeg sellises tsüklis, kas pole see erinev olukorrast, mil tuleb igaveses tsüklis istuda 364 päeva palmi all ja üks päev katlas. Nende kahe olukorra kvaliteet on täiesti erinev ja kellelgi meist pole raske nende vahel valikut teha.

Ma tahaks öelda, et teadlased olid igaveste karistuste üle arutledes kimpus terve hulga probleemidega ning lõpmatuste matemaatika, mis natukenegi võimaldanuks analüüsi, oli tollal alles tekkimas.

Roomet Jakapi: Tõepoolest, see on periood, mil matemaatikud hakkasid tõsisemalt tegelema lõpmatuse problemaatikaga. See ärritas õige paljusid teolooge. Teoloogidele võis tunduda, et nende käest krabatakse midagi olulist ära, sest sinnamaani oli lõpmatuse teema käsitlemine olnud teoloogia privileeg.

Enn Kasak: Aristotelese traditsiooni järgi võeti kasutusele potentsiaalse lõpmatuse mõiste. Tavaliselt, kui teadlane rääkis lõpmatusest, rääkis ta potentsiaalsest lõpmatusest. Selline lõpmatus on lihtsalt suurem kui ükskõik milline etteantud arv, või siis väiksem kui ükskõik milline etteantud arv. Aristotelese järgi ei suuda ma aru saada lõpmatusest, aga ma võin ette kujutada, et see on suurem (või väiksem) ükskõik millest. Selline lõpmatus sarnaneb liikumisega lõpmatusse. Aga see "päris" täielik lõpmatus - aktuaalne lõpmatus, seda siis samastati mõnes mõttes metafüüsilise lõpmatusega ehk Jumalaga, ning see oli siis tõepoolest teoloogide pärusmaa. Aga ka tänapäeval öeldakse, et kui füüsikud ähkides-puhkides mäetipule jõuavad, avastavad nad eest teoloogid, kes on juba sajandeid oodanud.

Nüüd jõuame tegelikult tagasi sinna, kust me seda arutelu alustasime. Ikka sellesama juurde, milles siis seisneb teaduslik uskumus või teaduslik teadmine. Miks juhtub nii, et tänapäeval n-ö nülitakse tõesti Newtonilt maha väga oluline osa tema loomingust, ei räägita midagi tema müstilistest töödest ja miks see tendents on võib-olla üldine. Võtame mõne teise füüsiku, tänapäeva füüsiku, näiteks Einsteini, kellest on tehtud peaaegu et jumal, täpsemalt teaduspühak. Legendi järgi oli 20. sajandil selline füüsik nagu Einstein, ja see on nüüd geeniuse musternäidis, kellest alates on kõik muutunud ja hoopis teistsuguseks saanud. Ja ta tõstetakse nii 
kõrgele postamendile, et jäävad märkamata teised geeniused, kes ei olnud sugugi rumalamad, ning Einsteini suurtest eksitustest ei räägita mitte ühtegi sõna.

Roomet Jakapi: Einsteinist tehti üks 20. sajandi suurimaid staare Marilyn Monroe kõrval.

Enn Kasak: Jah seda on selgelt tunda. Siin ja praegu pole muidugi õige koht Einsteini mahategemiseks, kuid ütleks siiski, et nii kõrget postamenti ta teiste geeniuste kõrval kindlasti ära teeninud ei ole. Selle taga seisab vajadus kedagi kummardada. Ja kui kedagi juba peetakse endast paremaks, siis pannakse ta kohe niipalju endast paremaks ja targemaks, et noh meil pole ju lootustki tema tasemel olla.

Umbes samuti oli varem Newtoniga, kes oli mõtleja tollest perioodist, millest me siin räägime. Newtoni loodud maailmasüsteem oli paljude arvates võimeline nii paljusid asju käsitlema ja seletama, et samamoodi tõsteti temagi võrreldamatult kõrge postamendi otsa, teistel polnud nagu lootustki talle vastu saada. Nii küpsetatakse teaduspühakuid. Muidugi olid Newtoni mõtlemises olemas mõned tõepoolest väga olulised momendid. Näiteks seesama õuna kukkumise lugu, mille autoriks oli William Stuckley, pähekukkumisest seal nüüd küll juttu ei olnud, kuid ta olla tõesti vaadanud õunte kukkumist, ja siis aru saanud, et tegemist on sama jõuga, mis liigutab Kuud taevas. Ühesõnaga, ta mõtles Kuu liikumise teooria üle. Kepleri seadused oli selleks ajaks juba teada, Newton püüdis mõista, mis võiks neid seadusi siis põhjustada. Ta otsis põhjusi seadustele, ja see ei ole üldse niiväga tavalise teadlase moodi. Võibolla selle eest võiks Newtoni tõesti ka postamendile tõsta. Tavaline teadlane nii väga ei mõtlegi loodusseaduste loomuse üle, ta kipub kiiresti rehkendama või pigem püstitab mingisuguse paremini lahendatava probleemi.

Kui mõeldi Kuu liikumise ja õuna kukkumise peale, siis pigem nii, et üks asi on Kuu liikumine taevas ja teine asi on ouna mahapotsatamine. Ja neid on alati käsitletud täiesti erinevate asjadena. Aristotelesest alates oli ju selge, et kõik asjad alates Kuu orbiidist peavadki käima ringjoont mööda: kui me laseme tüki kuuainet lahti, siis see hakkab mööda ringjoont liikuma ümber universumi keskpunkti. Aga kui me võtame tüki maad või tüki vett või õuna, siis see kukub allapoole. Neid tulebki erinevalt käsitleda. 
Siin peaks hea sõnaga meelde tuletama Giordano Brunot, kes taastas materiaalse ühtsuse universumis, kelle järgi pole vahet Kuu-alusel ja Kuu-pealsel maailmal. Ta tõi sisse sellised kosmoloogilised printsiibid, et maailm on ühesugune, enamasti kõikides suundades üheväärne, enam-vähem ühesuguse ainega täidetud ja materiaalselt ühtne. Ja see võimaldas Kuud ja õuna näha ühes võtmes, see oli aluseks, et Newton võis oma idee peale tulla, mis oli loomulikult geniaalne samm. Kuid samas tegeles Newtongi salateadustega ja tema tegevuste kohta võiks paljugi öelda. Kuid tema kritiseerimiseks pole siin õige koht, tähtis on see, et ei ole vaja inimestest jumalaid või pühakuid teha, vaid nende tegevust tuleb vaadata kontekstis. Pole vaja arvata, et kui keegi tuli mingi asja peale, siis ta kindlasti peab olema see, kes kõnnib Jumala paremal käel, jalutab koos Jumalaga nagu püha Eenok, vaid et ta on ikkagi üks meie hulgast. Ta oli vaieldamatult võimekas ja osutus õigel ajal tegelema jõukohase tähtsa probleemiga, tal oli kindlasti ka õnne leida lahenduv probleem ja ta töö ei läinud kaduma. Rõõmustagem, et meie hulgas on selliseid, kuid ärgem tehkem neist ebajumalaid. Teadusel pole vaja pühakuid, ehk küll neid vajavad teadusideoloogid.

Roomet Jakapi: Samas ei maksaks ka jumalatest ja kuraditest ilmaasjata inimesi teha.

Enn Kasak: Jah muidugi, kuid ei tohi unustada, et (kristliku teoloogia järgi) inimene on ikkagi Jumala näo järgi tehtud, ja kuradiga paistab meid ühendavat vähemalt üks asi, see on kannatus. Kui kuradid viibivad põrgus, siis nad ei ole seal nii, nagu pilapiltidel kujutatakse: mees on katlas, kurat, viinapudel käes, torgib teda viglaga ja irvitab, ei, kuradid on seal ka karistuseks, seega on nad ka kaaskannatajad ja kannatus ongi mõnes mõttes see, mis meid ühendab. Seda võiks mõista nagu olukorda Vene armees. Seal on teatavasti dedovštšina probleem. Mõnes mõtte võib öelda, et see, kes piinab noorsõdurit, on piinatava kaaskannataja, sest temagi kannatab armeeteenistuse käes ja kannatus ühendab neid.

Roomet Jakapi: No ilmselt ikka ühendab, sest piinaja on varem ise kannatanud kuidagi. Siin on olemas analoogia põrguga.

Enn Kasak: Jah, just sellepärast ma selle näite tõin. 
Roomet Jakapi: Kokkuvõtteks võiks öelda, et sedalaadi maailma ajaskeem, mida me siin visandada püüdsime, alates maailma, loomade ja inimese loomisest ning lõpetades kas siis igavese õndsusega taevas või piinadega põrgus, püsis kindlalt varasema uusaja inimese meeles. Need jumalikud asjad, tõed ja sündmused sisaldusid tollaste inimeste maailmapildis küllalt selgepiirilisel kujul.

Enn Kasak: Mis on tähtis: nad sisaldusid maailmapildis tihti lausa usalduslikul tasemel. Nende üle mõtlemist sageli isegi ei teadvustatud. Taeva ja põrgu olemasolu oli iseenesestmõistetavana teadvuses olemas.

Järgmine kord püüame rääkida mikrokosmilisest ajaskaalast, hingest, kehast ja nende rännakutest.

Artikli alusmaterjaliks on Vikerraadios 2003. aastal Maris Johannese toimetatud raadiosaade. 